\title{
Effect of high hydrostatic pressures on antioxidant properties of mexican fig (ficus carica l.) paste
}

\begin{abstract}
The fig is a fruit with important nutritional and functional properties for human health. The aim of this study was to evaluate the impact of processing with high hydrostatic pressures (HPP) at different times and temperatures of pressurization on anthocyanin content and antioxidant capacity of fig paste. This work showed that HPP at $350 \mathrm{MPa}$ for 5,10 and $20 \mathrm{~min}$ at 20 and $40^{\circ} \mathrm{C}$ did not change total acidity, total soluble solids and color. However, pressurized samples at $350 \mathrm{MPa}$ for 5,10 and $20 \mathrm{~min}$ showed a significant increase in anthocyanin content compared to the control. The antioxidant capacity, measured by 2,2-azino-bis-3-ethylbenzatholine-6-sulfonic acid assay was not altered by HPP at different times, but when it was treated at $350 \mathrm{MPa}$ by 20 and $40^{\circ} \mathrm{C}$, this result was modified and had a significant increase when method of 2,2-diphenyl1-picrilhydrazil was used. These data demonstrate that the HPP can be used in the fig products generation with higher nutritional quality.
\end{abstract}

Keywords: fig paste, HHP, antioxidant capacity, anthocyanin, PPO
Volume I Issue 6 - 2017

\author{
Jorge Antonio Lira de la Mora,' Erick Sierra \\ Campos,' María Alejandra Sánchez-Muñoz,' \\ Jorge Armando Meza-Velázquez, José Alberto \\ Ramírez de León, ${ }^{2}$ Arturo Ragazzo-Sánchez, ${ }^{3}$ \\ Miguel Aguilera-Ortiz' \\ 'Universidad Juárez del Estado de Durango, México \\ ${ }^{2}$ Departamento de Ciencia y Tecnología de los Alimentos, \\ University in Reynosa, México \\ ${ }^{3}$ Instituto Tecnológico de Tepic, México
}

\begin{abstract}
Correspondence: Erick Sierra-Campos, Facultad de Ciencias Químicas, Universidad Juárez del Estado de Durango. Av. Artículo 123 S/N Fracc. Filadelfia. CP 35010 . Gómez Palacio, Durango, México, Tel (+52) 87I7I58810, Fax (+52) 8717158810, Email ericksier@gmail.com
\end{abstract}

Miguel Aguilera-Ortiz, Facultad de Ciencias Químicas, Universidad Juárez del Estado de Durango.Av.Artículo 123 S/N Fracc. Filadelfia. CP 350 I0. Gómez Palacio, Durango, México, Email maguilerao@ujed.mx

Received: November 28, 2017| Published: December 13, 2017

\section{Introduction}

Common fig (Ficus carica L.) belongs to the family Moracea. It is commonly known as fig, which is a medium-sized deciduous tree widely distributed in sub-tropical and tropical countries. The fig was introduced in Mexico by Spanish Franciscan missionaries in the $16^{\text {th }}$ century and it is assumed that Mexican figs are the Spanish cultivar Black Mission. ${ }^{1}$ This fruit has been used as medicine for several centuries, ${ }^{2}$ hence being an important harvest worldwide for its dry and fresh consumption. Moreover, fruits can be eaten canned, or in other preserved forms. ${ }^{3}$ However, these procedures may alter the phytochemical composition of the product.

Nowadays, there is a general trend to increase fresh fruit consumption mainly due to their health properties. Different studies have demonstrated that figs are an important source of minerals and vitamins such as iron, calcium, potassium, thiamin and riboflavin. ${ }^{4}$ Figs are free of sodium, fat and cholesterol; contain at least 17 amino acids and high concentrations of aspartic and glutamic acid. ${ }^{5,6}$ They also possess relatively high fiber content $(5.8 \%$, w/w), which more than $28 \%$ is soluble, and can help to lose weight and to control blood sugar and cholesterol. ${ }^{7}$ Dehydrated figs have the highest concentration of polyphenols when compared to regular fruits and generally consumed beverages. ${ }^{5}$ For all these characteristics, figs are really considered as functional foods. ${ }^{8}$

Thermal processing is traditionally used in food industries causing unwanted changes in food quality such as loss of aroma, color, flavor, texture and nutritional value. The use of high hydrostatic pressures (HHP) for food processing has increased its application by food industry. HHP is a non-thermal technology capable to produce high quality food, preserving the characteristics of fresh food and extending its shelf life. In addition, HHP have the ability to inactive microorganisms as well as enzymes responsible for shortening the life product while maintaining food sensorial and nutritional properties. ${ }^{9,10}$ However, in some cases, HHP may activate undesirable enzymes such as polyphenoloxidase (PPO) resulting in short shelf life due to flavor and color changes. ${ }^{11}$

Phenolic compounds are closely associated with the sensory and nutritional quality of fresh and processed foods. Among the chemical reactions that occur during fruits processing, phenolic compounds oxidation is a phenomena responsible for profound modifications of the initial plant polyphenols concentration. Since it is generally agreed that PPO is mainly responsible for browning, and its increased activity after peeling and cutting would be expected. ${ }^{12}$

Due fig is a climacteric fruit, very perishable, with high metabolic activity, fast ripening and reduced store time at room temperature, make difficult its commercialization. Furthermore, the industry of fresh-cut fruits and vegetables is constantly growing due to the current consumption needs for minimally processed foods. Therefore, new techniques for maintaining quality and inhibiting undesired microbial growth are demanded in all steps of the production and distribution chain. ${ }^{13}$ Thus, the application of HPP seems to be a good processing alternative for fig. The main aim of this work was to evaluate the effect of HPP on physicochemical properties, anthocyanin content and antioxidant capacity in fig paste (Black mission). 


\section{Materials and methods}

\section{Reagents}

ABTS reagent (2,2-azino-bis-3-ethylbenzthia-6-sulfonic acid), potassium persulfate and Trolox was purchased from Sigma-Aldrich. Anhydrous ethanol, anhydrous methanol, $\mathrm{HCl}$ and all other reagents were of analytical grade.

\section{Sample preparation}

Figs (Ficus carica L.), Black mission variety, were freshly cut and received from Huerto La Linda, S.P.R de R.L. of C.V. located in the Ejido Álvaro Obregón Lerdo Durango, Mexico. Figs were washed with fresh water and stored in a cooler with crushed ice, in a proportion less than $20 \%$ of the volume of fig to slow maturation without causing cold damage, until its use (less than 6 hours). Peduncle from fruit was removed with a knife and figs were liquefied without adding water in an industrial blender of $4 \mathrm{Kg}$ (International model LI-5 with serial number 037-ago-98). Liquefied samples were placed into a $60 \mathrm{~L}$ aluminum container where the whole fig batch was mixed and stored under refrigeration until processing (less than 12 hours). The homogenized fig paste was weighed $(100 \mathrm{~g})$ inside vacuum packing bags, impervious to oxygen and moisture, and vacuum sealed with a sealer (Food Saver ${ }^{\text {B }}$ model U3835 Bag Sealer). Bags were labeled and subjected to pressurization. Paste was always in contact with ice to prevent the growth of microorganisms. The samples already packed in vacuum were placed in warm water to reach the pressurization chamber temperature.

\section{Fig paste processing with high pressures}

Treatments were carried out in an isostatic press (Laboratory Cold Isostatic Press model LCIP402260NCEP1MLN) located in the Integral Food Laboratory of the Technological Institute of Tepic (Nayarit, Mexico) with a maximum pressure of $700 \mathrm{MPa}$. The pressure transmitted to the fluid was distilled water containing $5 \%$ (v/v) of ethylene glycol, according to the manufacturer's instructions. The time required to reach the desired pressure was independent of the pressure level $(350 \mathrm{MPa} / 4.18-5.29 \mathrm{~min})$ and the time of pressure relief was 15-43 seconds. The pressurization times reported in this study do not include an increase in pressure. Black mission samples were pressurized at $350 \mathrm{MPa}$ for 5,10 and $20 \mathrm{~min}$ at 20 and $40^{\circ} \mathrm{C}$. The pressurized samples at $0 \mathrm{~min}$, means to pressurize enough time to reach the pressure of $350 \mathrm{MPa}$ and at that time the pressurization is suspended. Control samples reached room temperature (20 or $40^{\circ} \mathrm{C}$ ) and were cooled again. After processing, samples were stored at $-20^{\circ} \mathrm{C}$ until its analysis. The experiments were developed using homogenized samples of each of two fig varieties and analyzed by triplicate.

\section{Extraction and quantification of anthocyanins}

To determine the total anthocyanin content, approximately $1 \mathrm{~g}$ of fig paste sample was weighed in a $25 \mathrm{~mL}$ Erlenmeyer flask and a solution to extract anthocyanins $(10 \mathrm{~mL})$ was added $(\mathrm{HCl}$ : methanol: water: $0.02: 8: 1.8 ; \mathrm{v} / \mathrm{v} / \mathrm{v})$. The flask was placed in a sonicator at $50^{\circ} \mathrm{C}$ for $1 \mathrm{~h}$. The extract was centrifuged at $3000 \mathrm{rpm}$ for $10 \mathrm{~min}$ at $4^{\circ} \mathrm{C}$ and supernatant was collected and stored in an amber vial at $4^{\circ} \mathrm{C}$ until its use. Finally, absorbance was measured at a wavelength of $525 \mathrm{~nm}$ and total anthocyanins concentration in fig paste was reported as $\mu \mathrm{g}$ equivalent of cyanidin 3-glucoside/g of fig paste.

\section{Total antioxidant capacity}

Antioxidant capacity was evaluated using the ABTS method according to Nenadis et al. ${ }^{14}$ A $7 \mathrm{mM}$ aqueous solution of ABTS and a $140 \mathrm{mM}$ solution of potassium persulfate were prepared. Then, $88 \mu \mathrm{L}$ of potassium persulfate were mixed with $5 \mathrm{~mL}$ of ABTS and left to rest in the dark for $12 \mathrm{~h}$. Then, $500 \mu \mathrm{L}$ of the activated radical was taken and mixed with $25 \mathrm{~mL}$ of ethanol. The absorbance was determined at $734 \mathrm{~nm}$ and adjusted from 0.7 to 1 if necessary. The calibration curve of Trolox was used in a range of $0.5-8 \mu \mathrm{M}$ from a methanolic solution of Trolox sonicated for 5 minutes.

The inhibition percentage of DPPH was calculated as follows:

DPPH inhibition $(\%)=[(\mathrm{A} c t r l-\mathrm{A}) / \mathrm{A} \mathrm{ctrl}] * 100$

Results are expressed as antioxidant activity equivalent to Trolox ( $\mu \mathrm{M}$ Trolox/100g of paste).

For DDPH determinations of fig paste samples, a plate containing the calibration curve and samples was read at $520 \mathrm{~nm}$ in an Elisa reader by following kinetic times of $0,4,10,30,60$ and $90 \mathrm{~min}$ until the percentage of inhibition of the antioxidant (Trolox) was observed. Different Trolox alcoholic solutions were used for calibration curves and the analyses were performed in triplicate and results were expressed as DPPH inhibition percentage.

\section{Statistical analysis}

Data were analyzed by Statistica for Windows version 7.0 applying two-way analysis of variance and differences between means were determined $(\mathrm{P}<0.05)$ using Duncan's multiple range test.

\section{Results and discussion}

Diverse studies on change in the state of food products have shown the impact of the quality of processing methods on the organoleptic properties (e.g. taste, texture, smell and appearance). The color is an intrinsic property of foods, and therefore, a change in color and often caused by change in quality. While other important quality attribute of processing figs is titratable acidity because the presence of citric, acetic and a small quantity of malic acids has been reported in figs and the level of acid contributes markedly to the flavor of the products. ${ }^{15}$ This study showed that HPP at $350 \mathrm{MPa}$ for $0,5,10$ and $20 \mathrm{~min}$ at 20 and $40^{\circ} \mathrm{C}$ did not change total acidity, total soluble solids and color (data not shown).

Figs are an important source of anthocyanins. In this study, the total anthocyanins content of fig paste at different pressurized-times are summarized in Table 1. Their values range from 237.3 to $271 \mu \mathrm{g} / \mathrm{g}$ of paste. Thus, the total anthocyanins content was significantly increased with increasing pressurized time $(\mathrm{P}<0.05)$. The fig paste at $10 \mathrm{~min}$ of pressurized time, showed the highest total anthocyanins when compared to other treatments. In this study, the content of anthocyanins did not change significantly in all the samples treated at different temperatures $\left(20\right.$ and $\left.40^{\circ} \mathrm{C}\right)$ at $350 \mathrm{MPa}$. However, pressurized samples at $350 \mathrm{MPa}$ at different times $(0,5,10$ and $20 \mathrm{~min})$ showed a significant increase in anthocyanin content compared to the control. In these samples, the contents were significantly higher (5$14 \%$ ) and may be the result of cell disruption caused by pressure and leading to a higher extractability of these compounds. ${ }^{16}$

The effect of HHP on anthocyanins content has been well studied. When products rich in polyphenols and anthocyanins are pressurized, 
anthocyanins content is affected and increased with processing conditions (temperature and time). ${ }^{17}$ These results are agreed with Corrales et al. ${ }^{18}$ who have demonstrated the increase in anthocyanins recovery when HPP are applied. However, lower anthocyanin content was observed in samples treated for $20 \mathrm{~min}$ and it may be due to a remaining activity of enzymes such as PPO and $\beta$-glucosidase, due PPO is a stable enzyme to pressure, which oxidizes polyphenols (anthocyanins) generating dark compounds. In addition, García et al. ${ }^{19}$ observed the activation of this enzyme in red raspberries treated at $600 \mathrm{MPa}$ for $10 \mathrm{~min}$. However, PPO and other peroxidases are inactivated by applying a pressure equal or greater than $400 \mathrm{MPa}$ in combination with temperatures between 20 to $90^{\circ} \mathrm{C}$. Under these conditions, PPO activity can be reduced by up to $50 \%$, although the percentages may vary depending on intrinsic properties of processed foods. ${ }^{20}$

Table I Anthocyanins content in pressurized and non-pressurized fig paste

\begin{tabular}{ll}
\hline Time (min) & $\begin{array}{l}\text { Anthocyanins content } \\
\text { ( } \boldsymbol{\mu g} \text { of Cyanidin 3-glucoside/g of Fig Paste) }\end{array}$ \\
\hline 0 & $233.59^{\mathrm{b}}$ \\
5 & $251.68^{\mathrm{ab}}$ \\
10 & $271.08^{\mathrm{a}}$ \\
20 & $266.20^{\mathrm{a}}$ \\
Control & $237.3 \mathrm{I}^{\mathrm{b}}$ \\
\hline
\end{tabular}

Mean with different letter are significative different, $p=0.029$.

Generally, temperature is one of the most important factors affecting antioxidant activity. The antioxidant capacity of a substance is reflected by its ability to scavenge reactive oxygen species and reactive electrophiles. The antioxidant capacity of the fig paste was $376.7 \mu \mathrm{mol}$ Trolox/100g of paste by ABTS. The antioxidant capacity of our treatments decreased when temperature is increased (Figure 1). HPP had a light negative effect on the antioxidant capacity measured by ABTS, reducing the antioxidant capacity by $21.5 \%$ when the pressurization temperature was raised from 20 to $40^{\circ} \mathrm{C}$. As shown in Figure 1A, from 0 to $5 \mathrm{~min}$ of pressurization at $40^{\circ} \mathrm{C}$, antioxidant capacity was increased, but from 10 to $20 \mathrm{~min}$ a slight decrease in antioxidant activity was observed. The decrease in antioxidant capacity can be the result of eliminating part of enzymatic oxidation, responsible for polyphenols and anthocyanins loss.

A number of methods are used to determine the radical scavenging effects of natural compounds with antioxidant properties. DPPH method is a preferred procedure due it is fast, easy and reliable and does not require a special reaction or device. When the stable DPPH radical accepts an electron from the antioxidant, a violet color of the DPPH is reduced to yellow which is measured spectrophotometrically. All treatments showed same level of DDPH radical scavenging activity, about $49.3 \%$ of antiradical activity by inhibition of DPPH. HHP treatment increased antioxidant activity in fig paste, which ranged from 50 to $60 \%$. Thus, the DPPH method showed an increase of $14.4 \%$ of the antioxidant capacity after $5 \mathrm{~min}$ at $350 \mathrm{MPa}$ (Figure $1 \mathrm{~B}$ ) and a $9.4 \%$ raise when the pressurization temperature ranges from 20 to $40^{\circ} \mathrm{C}$.

It has been shown that the effect of HHP on antioxidant capacity depends on the treated product. For instance, Patras et al. ${ }^{21}$ reported higher antioxidant capacity of blackberry puree after pressurization, but found no effect of the process on strawberry puree. Tomato and carrot purees subjected to HHP presented higher antioxidant capacity than unprocessed samples. ${ }^{22}$ Cao et al..$^{23}$ studied the total phenolic levels of strawberry pulps submitted to HHP, at 400MPa there was a decrease in total phenolic content regardless the time of HHP treatment.

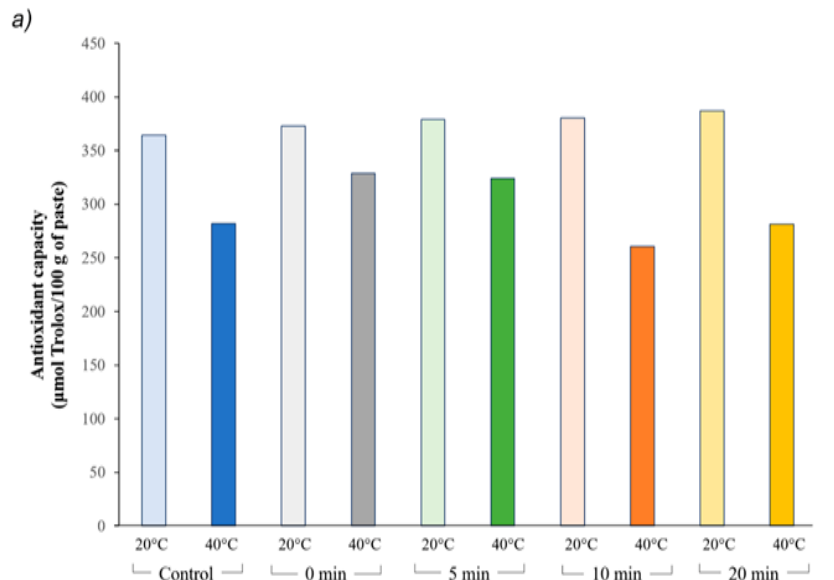

b)

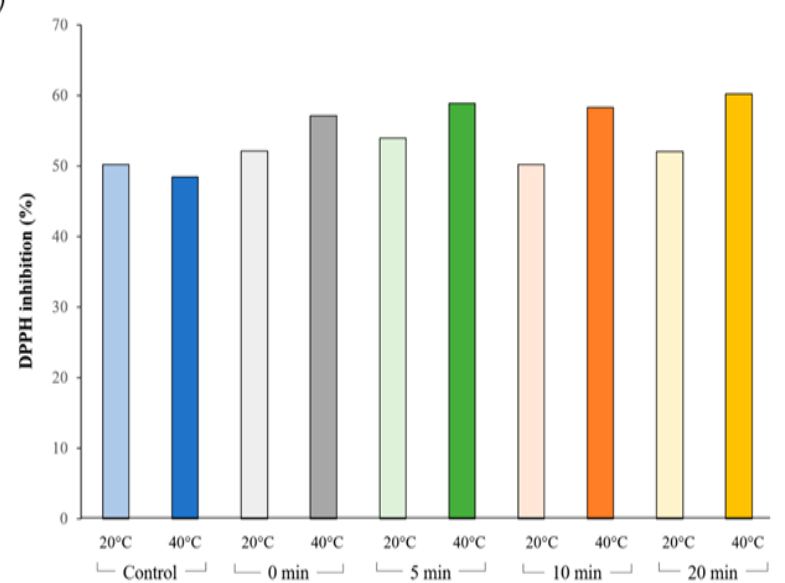

Figure I Effect of different temperature and time of pressurization on antioxidant properties of fig paste.

a. Antioxidant capacity with ABTS

b. DPPH radical scavenging activity of pressurized and non-pressurized fig paste. Data were expressed as mean. Values are significative different at $\mathrm{P}<0.05$.

\section{Conclusion}

Time and temperature of HHP treatment showed the strongest influence on anthocyanin content and antioxidant activity. Thus, our results suggest that $10 \mathrm{~min}$ of $\mathrm{HPP}$ at $20^{\circ} \mathrm{C}$ would be appropriate operating conditions to produce favored anthocyanin levels, antioxidant capacity and scavenging activity in fig paste.

\section{Acknowledgements}

This research was partially supported by Programa para el Desarrollo Profesional Docente (PRODEP grant UJED-2016, SESMéxico). 


\section{Conflict of interest}

The authors declare that there is not a conflict of interests regarding the publication of this paper.

\section{References}

1. García-Ruiz M, Mendoza-Castillo VM, Valadez-Moctezuma E, et al. Initial assessment of natural diversity in Mexican fig landraces. Genet Mol Res. 2013;12(3):3931-3943.

2. Ivanov I, Nadezhda P, Dencheva N, et al. Phytochemical and pharmacological investigations of ficus carica L. (Fig). Scientific Works of University of Food Technologies. 2014;61:362-365.

3. N MC. In gardens of Hawaii. USA: University of Hawaii and Bishop museum; 1965.

4. Slatnar A, Klancar U, Stampar F, et al. Effect of drying of figs (Ficus carica $L$.) on the contents of sugars, organic acids, and phenolic compounds. J Agric Food Chem. 2011;59(21):11696-11702.

5. Solomon A, Golubowicz S, Yablowicz Z, et al. Antioxidant activities and anthocyanin content of fresh fruits of common fig (Ficus carica L.) J Agric Food Chem. 2006;54(20):7717-7723.

6. Veberic R, Colaric M, Stampar F. Phenolic acids and flavonoids of fig fruit (Ficus carica L.) in the northern Mediterranean region. Food Chemistry. 2008;106(1):153-157.

7. Bose TK, Mitra S. Fruits: Tropical and Subtropical. India: Naya prokash; 1990. p. 1-838.

8. Vinson JA, Zubik L, Bose P, et al. Dried fruits: excellent in vitro and in vivo antioxidants. J Am Coll Nutr. 2005;24(1):44-50.

9. Lopes ML, Valente Mesquita VL, Chiaradia AC, et al. High hydrostatic pressure processing of tropical fruits. Ann N Y Acad Sci. 2010;1189:615.

10. San Martin MF, Barbosa-Cánovas GV, Swanson BG. Food processing by high hydrostatic pressure. Crit Rev Food Sci Nutr. 2002;42(6):627645.

11. Duong T, Balaban M, Perera C. Effects of combined high hydrostatic pressure and dense phase carbon dioxide on the activity, structure and size of polyphenoloxidase. J Food Sci. 2015;80(11):E2486-E2494.

12. Lattanzio V, Cardinali A, Palmieri S. The role of phenolics in the postharvest physiology of fruits and vegetables: browning reaction and fungal diseases. Italian Journal of food science. 1994;6(1):1-22.
13. Allende A, Tomas-Barberan FA, Gil MI. Minimal processing for healthy traditional foods. Trends in Food Science \& Technology. 2006;17(9):513-519.

14. Nenadis N, Wang LF, Tsimidou M, et al. Estimation of scavenging activity of phenolic compounds using the ABTS $\bullet+$ assay. J Agric Food Chem. 2004;52(15):4669-4674.

15. Shiraishi S, Kawakami K, Widodo SE, et al. Organic acid profiles in the juice of fig fruits. Journal-Faculty of Agriculture Kyushu University. 1996;41(1/2):29-34.

16. Van Eylen D, Oey I, Hendrickx M, et al. Effects of pressure/temperature treatments on stability and activity of endogenous broccoli (Brassica oleracea L. cv. Italica) myrosinase and on cell permeability. Journal of food engineering. 2008;89(2):178-186.

17. Ferrari G, Maresca P, Ciccarone R. The effects of high hydrostatic pressure on the polyphenols and anthocyanins in red fruit products. Procedia Food Science. 2011;1:847-853.

18. Corrales M, Toepfl S, Butz P, et al. Extraction of anthocyanins from grape by-products assisted by ultrasonics, high hydrostatic pressure or pulsed electric fields: a comparison. Innovative Food Science \& Emerging Technologies. 2008;9(1):85-91.

19. Garcia-Palazon A, Suthanthangjai W, Kadar P, et al. The effects of high hydrostatic pressure on $\beta$-glucosidase, peroxidase and polyphenoloxidase in red raspberry (Rubus idaeus) and strawberry (Fragaria $\times$ ananassa). Food Chemistry. 2004;88(1):7-10.

20. Bello EFT, Martínez GG, Ceberio BF, et al. High pressure treatment in foods. Foods. 2014;3(3):476-490.

21. Patras A, Brunton N, Da Pieve S, et al. Effect of thermal and high pressure processing on antioxidant activity and instrumental colour of tomato and carrot purées. Innovative food science \& emerging technologies. 2009;10(1):16-22.

22. Patras A, Brunton NP, Da Pieve S, et al. Impact of high pressure processing on total antioxidant activity, phenolic, ascorbic acid, anthocyanin content and colour of strawberry and blackberry purées. Innovative Food Science \& Emerging Technologies. 2009;10(3):308-313.

23. Cao X, Zhang Y, Zhang F, et al. Effects of high hydrostatic pressure on enzymes, phenolic compounds, anthocyanins, polymeric color and color of strawberry pulps. J Sci Food Agric. 2011;91(5):877-885. 